\title{
The human right to water and sanitation: a new perspective for public policies
}

\author{
Direito Humano à agua e ao esgotamento sanitário: \\ uma nova perspectiva para as políticas públicas
}

Colin Brown ${ }^{1}$

Priscila Neves-Silva ${ }^{1}$

Léo Heller ${ }^{1}$
${ }^{1}$ Centro de Pesquisas René Rachou, Fundação Oswaldo Cruz. Av. Augusto de Lima 1715, Barro Preto. 30190002 Belo Horizonte MG Brasil.colin.brown@ cpqrr.fiocruz.br

\begin{abstract}
The recognition of the human right to water and sanitation (HRtWS) by the United Nations General Assembly and Human Rights Council in 2010 constituted a significant political measure whose direct consequences are still being assessed. Previous to this date, the HRtWS and its link to a healthy life and adequate standard of living had been recognised in diverse legal and judicial spheres worldwide, in some cases under the pressure of the initiatives of strong social movements. However, while the HRtWS is recognised by the UN State Members, it constitutes a concept in construction that has not been approached and interpreted in consensual ways by all concerned stakeholders. The present article presents a formal definition of this right with a base in human rights regulation. It attempts to dialogue with the different existing perspectives regarding the impact of its international recognition as a human right. It then elucidates the progressive development of the HRtWS in law and jurisprudence. Finally, it considers the urgency and challenge of monitoring the HRtWS and discusses important implications for public policies.
\end{abstract}

Key words Human rights, Access to water, Access to sanitation, Public policies
Resumo $O$ reconhecimento do direito humano à água e ao saneamento (HRtWS) pela Assembleia Geral das Nações Unidas e pelo Conselho de Direitos Humanos, em 2010, constitui uma medida política significativa cujas consequências diretas ainda estão sendo avaliadas. Anterior a esta data, a relação entre HRtWS com uma vida saudável e um padrão de vida adequado já havia sido reconhecida em diversas esferas legais e jurídicas em todo o mundo, em alguns casos devido à pressão das iniciativas de movimentos sociais fortes. No entanto, mesmo que o HRtWS tenha sido reconhecido pelos Estados Membros das Nações Unidas, ele constitui um conceito em construção que não tem sido abordado e interpretado de maneira consensual por todos os atores interessados. $O$ presente artigo apresenta uma definição formal desse direito com base no regulamento de direitos humanos. Tenta dialogar com as diferentes perspectivas existentes sobre o impacto do seu reconhecimento internacional como um direito humano. Em seguida, esclarece o desenvolvimento progressivo dos HRtWS na lei e na jurisprudência. Por último, considera a urgência e o desafio de monitorar os HRtWS e discute implicações importantes para políticas públicas.

Palavras-chave Direitos humanos, Acesso à água, Acesso ao esgoto, Políticas públicas 


\section{Introduction}

The human right to water and sanitation (HRtWS) has recently been the object of theoretical questionings, empirical evaluations and debates anchored in the relevant judicial and legal frameworks. A resolution for the HRtWS was initially rejected by the United Nations General Assembly (GA) in 2008. But two years later, renewed efforts succeeded in explicitly recognizing the HRtWS in the General Assembly's resolution 64/292 (28 July 2010) ${ }^{1}$ and the Human Rights Council's (HRC) resolution 15/9 (6 October 2010) $)^{2}$.

In resolution 64/292, the UNGA recognised the right to safe and clean drinking water and sanitation as a human right that is essential for the full enjoyment of life and all human rights ${ }^{1}$. This resolution can be understood as an extension of other human rights-related resolutions, such as the Vienna Declaration and Programme of Action ${ }^{3}$, which establishes that human rights are universal and inalienable; indivisible; interdependent and interrelated, including the right to development.

In resolution 15/9, the UNHRC also reaffirmed that the human right to safe drinking water and sanitation is derived from the right to an adequate standard of living and inextricably related to the right to the highest attainable standard of physical and mental health, as well as the right to life and human dignity ${ }^{4}$. For Bulto ${ }^{5}$, appropriate access to water for human consumption and sanitation acquired an authoritative status through General Comment n. 15, emitted by the United Nations Committee for Economic, Social and Cultural Rights (CESCR) ${ }^{6}$ in 2002. This author argues for the legitimacy of the CESCR's interpretation of the corresponding covenant in light of the prevailing international legislation on the environment and water, respectively, as well as the evolving legislative practices of the UN's State Members.

The specific regulation for the HRtWS has been modelled using the concept of normative content. For the human right to water, the applicable normative content is composed of the following five criteria: availability; accessibility; quality and safety; affordability; and acceptability. For the human right to sanitation, the same criteria are considered with adapted definitions for this service's specificities ${ }^{6}$. Mainly, the content of dignity and privacy apply, which are related to people's social and cultural standards, and take into consideration such gender-related particularities as the use conditions of women and young girls?
In addition to the normative content, general human rights principles must also be rigorously observed, including those of equality and non-discrimination, access to information and transparency, participation, accountability, sustainability, and progressive realisation and non-retrogression. States are also required to realise human rights in a progressive fashion, using the maximum amount of available resources ${ }^{6}$. This simultaneously represents an opportunity to maintain States' accountability and a challenge for monitoring their efforts.

Although the HRtWS is recognised by the UN State Members, it constitutes a concept in construction that has not been approached and interpreted in consensual ways by all concerned stakeholders. In this context, the present article presents a formal definition of this right with a base in human rights regulation, and attempts to dialogue with the different existing perspectives regarding this concept. It seeks to show that in spite of some controversies, this concept presents the important possibility of reorienting water- and sanitation- related public policies to make them adopt more inclusive approaches that produce more democratic outcomes. In the next section, we will present the factors that explain the introduction of the HRtWS and the implications of its recognition. Subsequently, we will elucidate how different interests are capable of appropriating this concept and the related concerns. The following section broadly discusses the progressive development of the HRtWS in legal and judicial spheres worldwide. Finally, we will discuss important aspects related to monitoring the progress of these rights worldwide. In conclusion, we argue that this concept may contribute to redefining the debate on public policies for water supply and sanitation.

\section{Why human rights to water and sanitation?}

Water has been perceived in many differing ways throughout the years, receiving various qualifiers: a public resource, a common pool resource, a flux or flow resource ${ }^{8}$, a non-substitutable resource ${ }^{9}$, an economic good ${ }^{10}$. Whether or not water as a substance is considered an inherently public or private good, some parties insist on the economic value of the water required by humans (i.e. drinking water) in light of its relationship with a plethora of aspects involved in water and sanitation provision, such as the technologies, infrastructure and labour needed to produce and supply these services. In fact, for 
some it is precisely this resource-intensive characteristic (as opposed to a cost-free one) that puts these human rights under the umbrella of economic, cultural and social rights ${ }^{11}$. However, increasingly strong movements are growing and coordinating among themselves worldwide for all the aspects involved in water and sanitation service (WSS) provision to be treated as public goods, which is represented as the framework that is most likely to realise the HRtWS. This vision has given rise to various interpretations, including that service provision should not be profit-oriented, that the privatisation of services should be abolished, and even that these services should be provided free of charge.

There is no doubt that discussions on WSSs have gravitated heavily around which governance models should structure service provision: what goods should be placed under ownership, whose ownership this might be, which parties should be responsible for executing service provision, and the overall financial structure of service provision (e.g. how to charge - or not charge - people for use; should States supply minimum quantities of free water?). Amidst these discussions, a major political issue at stake across the world, and perhaps the greatest challenge to defenders of the human rights to water and sanitation, consists in establishing appropriate and sustainable WSS services to under- or un-served persons, and providing affordable access to individuals without sufficient purchasing power ${ }^{12}$.

A valid question one may ask is "why human rights to water and sanitation now?" Catarina de Albuquerque ${ }^{7}$, the former Special Rapporteur on the human right to safe drinking water and sanitation (SRHRtWS), posited that this human right could have been explicitly recognised long ago when the International Covenant on Economic, Social and Cultural Rights (ICESCR) was designed and adopted by the UNGA in 1966. However, [m]any countries whose populations suffered from a lack of access to water and sanitation were not directly represented at the negotiating table ${ }^{7}$. More recently, the human right to water and sanitation has been referred to as a strategy, approach ${ }^{13}$, or idea ${ }^{14}$ by some, while others ${ }^{15}$ have focussed on its internationally established foundation as a sort of transcending truth or value that must necessarily inform politics.

It is to be noted that the $\mathrm{UNGA}^{1}$ and UNHRC's ${ }^{2}$ respective 2010 resolutions did not pass with the unanimous consent of all State Members. Many initially questioned, and some continue to question, the legal foundation of the
HRtWS ${ }^{16}$. The motives were numerous for forty-one countries to abstain from voting on the GA resolution (including the USA, UK, Canada, Australia, Sweden, Japan), plus the many more that were absent from the vote. Some affirmed that a distinct right to water does not exist under formal international law (e.g. the Universal Declaration of Human Rights, the ICESCR). For those State Members, such as the United States, that have still not even ratified the ICESCR, the implications of the $\mathrm{UNGA}^{1}$ and $\mathrm{UNHRC}^{2}$ resolutions are all the more disputable, as these State Members only technically remain obligated under UN regulation to not take measures that would make their signing this treaty redundant. Additionally, Gupta et al. ${ }^{14}$ highlight the perceived reluctance of some developing States to accept a direct responsibility to realizing these human rights on their territory, pointing out that the resolutions in which the HRtWS were initially recognised place considerable emphasis on the need for international cooperation in order to help developing countries in realizing these rights. For this author, it is worth wondering to what extent these specific conditions were in fact aspects that influenced many States to vote in favour of these resolutions as a strategic, development-oriented decision. Nevertheless, it should be noted that, since 2010, UN State Members have joined in consensus on several UNHRC and UNGA resolutions that reiterate the human right to water and sanitation.

Thus, it may be considered that many States' historical reluctance led to these rights' late formal, international recognition. The approval of the HRtWS in 2010 can be considered to be the fruit of a strong mobilisation led in large part by progressive social movements, and assisted by many States' committed to the development of human rights. Particularly, the fact that the $\mathrm{UNGA}^{1}$ resolution was introduced by the government of Bolivia was very symbolic, as it occurred amid an historic moment for this country, which was struggling for the national political sovereignty of its waters. In this context, the modern genesis of the HRtWS appears underscored by the mission of favouring under- and unserved populations and enforcing the principle of equality and non-discrimination.

\section{Appropriation of the concept by contrasting interests}

Water has become an increasingly discussed topic charged with the political and the econom- 
ic since its rise to the international podium in the 1970s (e.g. the 1972 Stockholm United Nations Conference on the Human Environment and the 1977 United Nations Mar del Plata Water Conference). Since the following decades, especially since the United Nations Dublin Conference in $1992^{10}$, the world has seen the rise of the tirelessly discussed neoliberal agenda and its particular applications to water management. Clarifying these terms, some consider that mainstream economics and the neoliberal agenda have been equivalent with a growth-oriented commoditisation of everything in society, including rights ${ }^{12}$. Albeit, for Bakker ${ }^{17}$, the establishment of the HRtWS and the applications that it has seen these past few years show signs of a transition into a hybrid post neoliberal agenda. Indeed, human rights constitute a strong, pro-poor political paradigm that, through its underpinning moral philosophy, intrinsically provokes a collision with neoliberalism, the most significant, perhaps dominating, paradigm in the contemporary world.

More and more efforts are being made to insert human rights into present and future politics. For instance, while human rights were conspicuously absent from the agenda for the Millennium Development Goals, the post-2015 agenda ${ }^{18}$ (embodied in the Sustainable Development Goals agenda, "Transforming our World"), on the contrary, clearly endorses the importance of human rights as a socio-political framework, making explicit reference to the human right to safe drinking water and sanitation. Yet, in the context of a global stage largely occupied by a neoliberal agen$\mathrm{da}$, it is becoming increasingly recognised that fundamental ideological contradictions make it difficult for these two paradigms to converge, if not at the drawing board, then at least on the ground. Some $\mathrm{e}^{19}$ have expressed doubts about the effectiveness of rights talk to provide imaginative language for thinking about new community economies and thus deny that the UN's recognition of the HRtWS has led to a significant improvement in the conditions of people whose access to WSSs is limited. Other authors ${ }^{12}$ affirm that the inherent commoditisation in mainstream economics is explicitly contradictory with a society that aims to enhance human rights: In this society accountability and universality are keywords and market ideology happens to ignore both. Human rights decline, or at least stagnation, should not be seen, therefore, as the outcome of doing wrongly the right econom$i c s$, but of rightly doing the wrong economics ${ }^{12}$.

Indeed, one seldom finds the concept of human rights within economic reasoning for the very reason that they do not share the same language and are incommensurable. Indeed, the UNGA's ${ }^{1}$ and UNHRC's ${ }^{2}$ resolutions on the HRtWS abstained from using firm economic language. As a consequence of becoming a human right, States assumed the ambiguous, and for that reason contentious, obligation to allocate their maximum available resources to the progressive realisation of these rights. Following in suit, the former SRHRtWS affirmed that there were no prescriptive models of service provision ${ }^{20}$. Thus, for some stakeholders, the resolutions represented a massive defeat for the Global Water Justice Movement, as the right to water remained compatible with private sector participation and contained no explicit obligation on utilities to provide subsidies or even a minimum quantity of free water to poor communities or, what might otherwise be necessary, to adopt financially unsustainable business models ${ }^{21}$.

Instead, the human rights principles of equality and non-discrimination, and the obligation of providing affordable services for all, suggest the need for policies that clearly define how services will be provided to the poor, which can be understood as policies that demand different forms of subsidies ${ }^{22,23}$. Thus, unsurprisingly, the above-mentioned resolutions have been adopted in differing ways by various stakeholders. While some development banks, industry and development aid agencies sometimes promote a particular interpretation of water as an economic good that endorses the need for full-cost recovery ${ }^{14}$, civil society organisations (e.g. WASH United, WaterAid, TNI) have been intensely adopting a conception of the HRtWS that prioritises first and foremost the extension of WSSs to society's most vulnerable demographics ${ }^{24}$.

In sum, the HRtWS remains a disputed concept that tends to be appropriated by different stakeholders in ways that correspond with their particular interests. Nevertheless, the concept is charged with the potential to point out the needs of society's most vulnerable groups and to influence the creation of clear policies with frameworks that provide all people with access to adequate WSSs.

\section{Progressive development in law and jurisprudence}

Human rights language regarding water and sanitation is being increasingly brought to judicial spheres throughout the world at various levels (national, regional, international, indepen- 
dent $)^{25}$. For some, increasing jurisprudence that addresses the human right to water contributes to legitimizing the recognition of these human rights. Indeed, throughout the past few decades, judges in various contexts have increasingly recognised the human right to water in a direct or indirect fashion, citing the inter-related nature of access to water with other human rights. In many cases a human right to water has not even been formally recognised in a respective nation's legislation. For example, in Ademar Manoel Pereira x Companhia Catarinense de Água e Saneamento $(\mathrm{CASAN})^{26}$, it was judged that the disconnection of a resident's water supply for non-payment amounted to a reprehensible, inhuman and illegal act, and that water supply, a fundamental public service, essential and vital for human beings [...] cannot be suspended for late payment of respective fees, as the public administration has reasonable means to recover use debts ${ }^{26}$.

However, advances in the judicial sphere in fact entail costly efforts that are not necessarily favourable to the broad representation of the disadvantaged people who suffer most from a lack of water and sanitation, a reality which, moreover, was recognised by the judge presiding over the previously cited case. Indeed, judicial recourse often demands interested specialists who are willing to deal with the cases of such people. Thus, where governments do not create enabling environments, it falls upon experts, NGOs or large social movements to bring "violations" to these spheres, which obviously does not result in universal coverage of all situations of violations, and can even be biased in the direction of those most connected to human rights defenders ${ }^{14,15}$.

Since the respective $\mathrm{UNGA}^{1}$ and $\mathrm{UNHRC}^{2}$ resolutions in 2010, State Members have been encouraged to adopt the HRtWS in their national legislation (e.g. UNGA resolution $68 / 157$ of

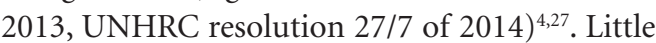
by little, countries have been increasingly doing so, some since even before the $2010 \mathrm{UNGA}^{1}$ and $\mathrm{UNHRC}^{2}$ resolutions (e.g. South Africa, Uruguay, Kenya). Meanwhile, critics raise concerns about the effectiveness of such measures on two main bases. Firstly, in some countries the human right to water and/or sanitation has been placed in constitutions, but their principles are not effectively applied to national laws, policies and regulations. For instance, Mexico has still not reformed its national waters law of 1992 although it amended its constitution to include the HRtW in 2010. In other nations, the HRtWS may be found in national laws, but practical outcomes still may not constitute the realisation of these human rights. Secondly, in connection with the previous point, States will also inevitably struggle to realise the HRtWS when, despite the principles of these human rights perhaps being found in national legislation, they coexist with other laws, policies and activities (most often economically interested) that are not favourable to these human rights.

Indeed, it appears necessary for States to have complete legal and political harmony as an overarching framework, notably including environmental laws and other economic policies (such as mining codes), in order to produce outcomes that effectively realise all human rights, and do not privilege some at the cost of others. Indeed, many States have long demonstrated unsustainable approaches to realizing the HRtWS. For instance, when confronted with inefficient or otherwise imperfect WSSs, instead of investing in maintenance and institutional reform, governments may choose to invest in system expansion, which in some cases may be unfavourable from an ecological point of view or contentious from a socio-political standpoint ${ }^{22}$. Where States operate in such fashion, they may often be only partially realizing the HRtWS, as they may not be fulfilling all of its principles, such as creating affordable services.

Furthermore, the concern exists that human rights are anthropocentric and, thus, may exclude ecological rights (the rights of non-humans $)^{28}$. Accordingly, the establishment of a human rights obligation to provide citizens with WSSs is feared to be able to lead some States to take risky decisions vis-à-vis human safety (e.g. extracting water from unsafe sources such as rivers) and/or inflicting further pressures on the already declining environment (e.g. strategically redirecting rivers to facilitate access to water ${ }^{29}$. However, it is important to recall the interrelated nature of all human rights and recognise, in the particular case of ecological concerns, that the normative content of providing safe, quality drinking water includes the human rights principle of sustainability. Indeed, the HRtWS must be considered together with the human right to a safe and healthy environment. In fact, the mandate of the Special Rapporteur on human rights and the environment is clear on this: protecting human rights helps to protect the environment $t^{30}$. Moreover, if it may represent any sign of their compatibility with a sustainable future, the clear inclusion of human rights in the internationally negotiated post-2015 development agenda 
(SDGs) should indicate their endorsement as a suitable framework to shape the planet's future ${ }^{18}$.

\section{The urgency and challenge of monitoring the HRtWS}

In the context of the SDGs' numerous timebased goals and the demand for rapid, measurable progress vis-à-vis the realisation of the HRtWS (among other human rights), critics have expressed doubt about the effectiveness of the recognition of these rights in this regard. Designed before the CESCR's general comment no. $15^{6}$ had even been formulated, the Millennium Development Goals were criticised ${ }^{31}$ as having defined arbitrary benchmarks (e.g. Target 7.C halving the total number of people without access to safe drinking water and sanitation). Moreover, the chosen eligibility criteria for what the program considered to be "improved" sources of water (e.g. any piped source arriving within a personal residence) were lambasted as they were often capable of providing unsafe water to users ${ }^{20,32}$. In sum, the goals lacked a framework that concretely aimed towards the realisation of these human rights ${ }^{20,33}$. Since then, the international post-2015 agenda (SDGs) is set to carve out a much more important place for the sustainable realisation of the HRtWS; its goals 6.1 and 6.2 aim, by 2030 , to achieve universal and equitable access to safe and affordable drinking water for all and, respectively, to attain access to adequate and equitable sanitation and hygiene for all, and to end open defecation, paying special attention to the needs of women and girls and those in vulnerable situations. In the case of the HRtWS, the new emphasis on sustainable solutions is undoubtedly a response to the concern that States previously focused more on achieving benchmarks (and perhaps doing so in the easiest way possible, according to the applicable criteria) than on developing lasting scenarios in which these rights would be realised in their territories ${ }^{34}$.

Yet, despite the improved formulation of goals in the post-2015 agenda, monitoring is still and will long be a crucial difficulty in ensuring the universal realisation of these rights. In particular, three important issues related to monitoring in the post-2015 agenda have been brought up in years past. First, it will be important to consider the gap between the (time-bound) goals and targets and the data available to measure whether the targets are being met. Satterthwaite ${ }^{33}$ highlights that while reporting on MDG progress was often annual, the surveys and censuses on which reporting relied took place every few years at best. Thus, increasing the availability of up-todate information will imply logistical and financial costs. Second, several parties ${ }^{35}$ have pointed out the need for increased diversity in indicators, including universal indicators for the human rights to water and sanitation. It is considered that additional criteria must be more effectively assessed, such as water quality (an estimated 1.8 billion people are still using a source of contaminated water ${ }^{36}$ although the MDG targets were met years in advance), inequality (e.g. developing indicators that take into account gender, religion, ethnicity, disability status, etc.), and progressive realisation (rather than level of achievement) ${ }^{35}$. Among other things, having this disaggregated data would help in specifically identifying not a mere percentage of people, but the precise individuals and groups that still lack access to safe drinking water and sanitation. A third monitoring difficulty concerns assessing the resources that States invest into advancing the realisation of the HRtWS, since States are understandably not obligated to immediately fulfil all of the criteria of the HRtWS normative content, but instead to progressively realise this human right with their maximum available resources. Even with the available data, which may not always be authentic and forthcoming, it remains difficult to establish a universal methodology that would allow authorities to perform a fair assessment of all States' efforts to realise the HRtWS based on this criterion.

Moreover, monitoring of the HRtWS is also performed through certain UN mechanisms. Signatory States to the United Nation's international human rights treaties are required to report to the appropriate human rights treaty bodies on their implementation efforts as an accountability measure. While State reporting of water and sanitation was previously submitted to the CESCR under the human right to adequate housing, since 2008 States must report specifically on the human right to water and sanitation. Moreover, since 2006 the United Nations Universal Periodic Review (UPR) process assesses information reflecting the fulfilment by each State of its human rights obligations and commitments, notably making use of the previously mentioned reports on treaty implementation efforts. However, in an assessment of this reporting process, Meier \& $\mathrm{Kim}^{37}$ voice concerns that State reporting to the CESCR has not significantly reflected an increased recognition of the normative content of the human rights to water and sanitation. Indeed, 
mandatory state reporting gives rise to two fears. One is that the categorically specific mention of these human rights could lead to States making mere lip service or falsely reporting. The second concerns the consequences of the adoption of a strictly quantitative reporting style, as demanded by the CESCR, which rejects "narrative" (a.k.a. qualitative) reporting ${ }^{37}$.

In this regard, the JMP's similarly categorical, quantitatively friendly use of "improved" or "non-improved" sources of WSSs has been unsurprisingly attacked for being simplistic and potentially unrepresentative of a worthwhile objective ${ }^{33}$. First, as stated previously, "improved" sources of water did not always provide safe drinking water, nor did these indicators necessarily help governments and service providers in pointing out precisely who was lacking drinking water and sanitation. However, in a more in-depth analysis, Satterthwaite ${ }^{33}$ demonstrates the value of narrative accounts ${ }^{38}$, explaining that in India, some apartment dwellers (often adolescent girls) who have flush toilets but do not have piped water suffer from chronic back pain from the task of having to haul water from public standpipes up multiple stories for flushing. On paper, such individuals apparently benefit from "improved" access to both water (public standpipes) and sanitation (pour-flush toilets) resources. Thus, these definitions did not measure equitable access as they contained several options (e.g. a household with a pit latrine and a slab is treated as equal to a household with their own WC with a sewer connection; a household with water piped on premises is treated as equal to access to a standpipe $e^{33}$ ) and more importantly did not allow for a more holistic reporting that could have clarified the still precarious, attendant conditions of access to WSS.

The new framework applied to the SDGs will measure safely managed water, sanitation and hygiene services instead of the improved services that were assessed in the MDGs. Thus, there is reason to believe that there will be increasing attention paid to the normative content and principles of the HRtWS. The important question that remains is to see what assessment strategy (i.e. indicators) will accurately reflect the fulfilment of human rights.

\section{Implications for public policies}

The vulnerable and disadvantaged sectors of the world's population are those that most lack safe, quality and affordable access to drinking wa- ter and sanitation services. As Sutherland et al. ${ }^{23}$ point out, inequalities often have clearly spatial characteristics. For example, an urban-rural gap exists worldwide. The differential costs involved in providing and maintaining quality service to urban centres and peripheries is often undeniable, as well as the existence of differential service provision to specific zones of an urban nucleus depending on its residents' socio-economic status. Furthermore, uncontrolled urbanisation creates difficult conditions to plan for WSSs a posteriori. The particular conditions that such groups face due to their lack of access highlights how the integration of the human rights approach in the formulation of public policies may create structuring conditions for greater social and environmental justice, improved public health and overall prosperity.

Precarious access to appropriate WSSs affects rural populations, who are society's most statistically marginalised, but also urban populations ${ }^{39}$. In rural areas, a lack of access to WSS has multiple implications, including an increased difficulty in undertaking income-producing activities, which in turn may lead to reduced family incomes, insufficient nutrition, and, consequently, various negative impacts on human health.

While the world's urban zones offer relatively better access to WSS, they are home to many people in situations of vulnerability who suffer daily from a lack of adequate access to these services, including street dwellers or people living in informal settlements. Between 1990 and 2012, the number of people living in cities who did not have access to improved WSSs increased from 111 million to 149 million and from 541 million to 754 million, respectively ${ }^{40}$. Indeed, access to drinking water is actually deteriorating where the most rapid urbanisation is outpacing public services $^{40}$. This has been favoured by the negative effects of property speculation of recent years passed and the rapid increase of urban populations, and especially of slums.

Within this context, the recognition of access to water and sanitation as human rights provides an opportunity to infuse this debate with democratic values, making society's citizens rights bearers who may seize the possibility to organise themselves on a political front to demand that their governments - the duty bearers - guarantee them their right. A parallel may be made here with the right to health, which, according to Paim ${ }^{41}$, is not a "natural" right. Instead, it was historically constructed and conquered through social movements, and, in many countries, is still 
threatened by economically driven policies that seek to reduce its scope. Similarly, the expansion of social movements could bring advances to the conquest of the HRtWS by reshaping public policies and reducing inequalities in access to WSSs. Indeed, Clark ${ }^{42}$ argues that community participation is essential to bring society's marginalised and vulnerable groups into the political sphere and, thereby, voice their demands for more equitable and inclusive services and public policies.

Social movements whose battles are grounded in participatory democracy are capable of incorporating guarantees that policies and programmes will be socially sustainable, equitable, focussed on all of society's needs, and will fulfil all of the principles and normative content related to these human rights. Indeed, participation of civil society is enshrined in many significant political engagements, including the Vienna Declaration and Programme of Action regarding human rights (1993), the Rio Declaration (1992) and the Dublin Statement (1992) concerning water and the environment, more specifically. Historically, social movements' battles have honoured social participation as a fundamental characteristic in performing democratic processes and strengthening the notion of citizenship, thereby honouring the very principle that underpins human rights and demonstrating the value of voicing and demanding one's rights. Free, active, and meaningful participation of citizens in decision-making processes, which recognises and values local-based knowledge, is a prerequisite for social groups to represent their needs and resulting demands. Furthermore, it stimulates interaction between groups and the sharing of opinions, experiences and knowledge $e^{43}$.

The absence of some of society's groups from decision-making processes establishes a risk of violating the principles of equality and non-discrimination, and contributes to the perpetuation of social exclusion and poverty. Moreover, social participation is closely related to other human rights principles, such as the right to participation and transparency, since complete access to information is a necessary condition for effective participation. Indeed, participatory approaches favour the expansion of democratic spaces and the increased strength of political measures or mechanisms, such as: transparent information; monitoring; complaints procedures; mobilisation; negotiation; lobbying and advocacy ${ }^{41}$, which are compatible with human rights principles and are valuable for the creation of sound public policies.

\section{Final considerations: the HRtWS and public policies}

The preceding discussion demonstrates in what aspects the HRtWS is still a concept in construction and, moreover, is part of a controversial process. It appears that one of the impacts that the recognition of these rights has had, especially as a result of the respective UN resolutions, has been the expectation that these measures would immediately remedy the dire conditions experienced by those who are excluded from adequate WSSs. Furthermore, the desire for these human rights to be formally recognised also seemed to be accompanied by an expectation that the corresponding regulation would either exclude any models of service provision with ties to the private sector ${ }^{19}$ or would immediately invoke a new economic logic of service provision that would guarantee affordable access to the poor ${ }^{44}$. However, the past few years have shown that the HRtWS is not a "magic wand" that can immediately transform the landscape of exclusion that has been a traditional characteristic of WSS provision to date. Indeed, the human rights principle of progressive realisation clearly does not require States to take drastically urgent measures. Nonetheless, the recognition of the HRtWS has not been equivalent with a merely symbolic change without any concrete effects.

In sum, we have argued that the following combination of factors and phenomena are creating a favourable climate for a change in the way that society approaches peoples' access to WSSs: the initiatives of social movements, changes to States' legal frameworks, the binding obligations of international law, judicial stances with respect to new legal regulations, and the new stances of service providers. The framework behind the HRtWS presents a new perspective for service provision $^{45}$. Moreover, the SDGs will also contribute to the creation of a new international climate capable of influencing a favourable modification in WSS service provision for society's most vulnerable and disadvantaged. Certainly, their recognition and application of the HRtWS framework will have a very positive effect, not only on the objectives with targets to improve the access to WSSs for all, but also for those to end poverty in all its forms everywhere; end hunger, achieve food security and improved nutrition; ensure healthy lives and promote well-being for all at all ages; ensure inclusive and equitable quality education and promote lifelong learning opportunities for all; achieve gender equality and empower 
all women and girls; promote sustained, inclusive and sustainable economic growth; reduce inequality within and among countries; make cities and human settlements inclusive, safe, resilient and sustainable; and promote peaceful and inclusive societies for sustainable development.

\section{Collaborations}

C Brown and P Neves-Silva worked in the design, research, writing and approval of the final version. L Heller worded in the design, research, preparation, critical review and approval of the final version.

\section{References}

1. United Nations General Assembly (UNGA). Human Right to Water and Sanitation. Geneva: UNGA; 2010. UN Document A/RES/64/292.

2. United Nations Human Rights Council (UNHRC). Resolution on the human right to safe drinking water and sanitation. Geneva: UNHRC; 2010. Resolution A/ $\mathrm{HRC} / \mathrm{RES} / 15 / 9$.

3. United Nations Human Rights Council (UNHRC). Vienna Declaration and Programme of Action. Vienna: UNHRC; 1993.

4. United Nations Human Rights Council (UNHRC). Resolution on the human right to safe drinking water and sanitation. Geneva: UNHRC; 2014. Resolution A/ HRC/RES/27/7.

5. Bulto TS. The emergence of the human right to water in international human rights law: Invention or discovery. Melbourne Journal of International Law 2011; 12(2):1-25.

6. United Nations Committee on Economic, Social and Cultural Rights (UNCESCR). General Comment No. 15: The Right to Water (Arts. 11 and 12 of the Covenant). Geneva: UNCESCR; 2003. UN Document E/C.12/2002/11

7. de Albuquerque C. Realizing the human rights to water and sanitation: a handbook by the UN Special Rapporteur Catarina de Albuquerque. Lisbon: UN; 2014.

8. Balanyá B, Brennan B, Hoedeman O, Kishimoto S, Terhorst P. Reclaiming Public Water: Achievements, Struggles and Visions from Around the World. Amsterdam: Transnational Institute; 2005.

9. Van der Zaag P, Savenije HHG. Water as an Economic Good: The Value of Pricing and the Failure of Markets. Delft: UNESCO-IHE Institute for Water Education; 2006.

10. United Nations Conference on Economic Development (UNCED). The Dublin Statement on Water and Sustainable Development. Rio de Janeiro: UNCED; 1992.

11. Salman MAS. The human right to water and sanitation: is the obligation deliverable? Water International 2014:39(7):969-982.
12. Branco MC, Henriques PD. The political economy of the human right to water. Review of Radical Political Economics 2010; 42(2):142-155.

13. McGranahan, G. For sanitation, a "rights-based approach" may be the wrong strategy. Open Democracy [Internet journal] 10 April 2015. [cited 2015 May 15]. Available from: https://www.opendemocracy.net/ openglobalrights/gordon-mcgranahan/for-sanitation- $\% \mathrm{E} 2 \% 80 \% 9$ Crightsbased-approach $\% \mathrm{E} 2 \% 80 \% 9$ D-may-be-wrong-strategy

14. Gupta J, Ahlers R, Ahmed L. The human right to water: moving towards consensus in a fragmented world. Rev Eur Commun Int Environ Law 2010; 19(3):294-305.

15. Winkler I, Roaf V. For sanitation, human rights are key to keeping governments accountable. Open Democracy [Internet journal]. 8 June 2015. [cited 2015 Jun 10]. Available from: https://www.opendemocracy.net/ openglobalrights/inga-winkler-virginia-roaf/for-sanitation-human-rights-are-key-to-keeping-governmen

16. United Nations. General Assembly Adopts Resolution Recognizing Access to Clean Water, Sanitation as Human Right, by Recorded Vote of 122 in Favour, None against, 41 Abstentions. UN.org [Internet Website]. 28 July 2010. [cited 2015 Sep 7]. Available from: http://www.un.org/ press/en/2010/ga10967.doc.htm

17. Bakker K. Neoliberal Versus Postneoliberal Water: Geographies of Privatization and Resistance. Annals of the Association of American Geographers 2013; 103(2):253260.

18. United Nations Department of Social and Social Affairs (UNDSSA). Transforming our world: the 2030 Agenda for Sustainable Development. Geneva: UNDSSA; 2015.

19. Bakker K. The "Commons" Versus the "Commodity": Alter-globalization, Anti-privatization and the Human Right to Water in the Global South. Antipode 2007; 39(3):430-455.

20. United Nations Human Rights Council (UNHRC). Report of the Independent Expert on the Issue of Human Rights Obligations Related to Access to Safe Drinking Water and Sanitation. Geneva: UNHRC; 2010. UN Document A/HRC/15/31. 
21. Global Water Intelligence. The human right to a national water plan. Global Water Intelligence [Internet website] 29 June 2010 [cited 2015 Aug 24]. Available from: www.globalwaterintel.com/insight/human-right-national-water-plan.html

22. United Nations Human Rights Council (UNHR). Report of the Special Rapporteur on the human right to safe drinking water and sanitation (On Affordability). Geneva: UNHR; 2015. UN Document A/HRC/30/39.

23. Sutherland C, Hordijk M, Lewis B, Meyer C, Buthelezi $\mathrm{S}$. Water and sanitation provision in eThekwini $\mathrm{Mu}-$ nicipality: a spatially differentiated approach. Environment \& Urbanization 2014; 26(2):1-20.

24. Wash United. Recognition of the human rights to water and sanitation by UN Member States at the international level. An overview of resolution and declarations that recognize the human right to water and sanitation. Wash United. org [Internet Website] Nov 2014 [cited 2015 Sep 29] Available from: http://www.wash-united.org/ files/wash-united/resources/States'\%20recognition_ HRWS_WEB_2015.pdf

25. Mirosa O, Harris LM. Human Right to Water: Contemporary Challenges and Contours of a Global Debate. Antipode 2012; 44(3):932-949.

26. Superior Tribunal de Justiça (STJ). Recurso Especial n 201.112 SC(99/0004398-7). 1999 April. [cited 2015 Aug 24]. Available from: https://ww2.stj.jus. br/processo/jsp/ita/abreDocumento.jsp?num_registro $=199900043987 \& d t \_$publicacao $=10-05-1999 \&$ cod_ tipo_documento

27. United Nations General Assembly (UNGA ). The human right to safe drinking water and sanitation. Geneva: UNGA; 2014. Resolution 68/157/2013.

28. Bakker K. Privatizing Water: Governance Failure and the World's Urban Water Crisis. New York: Cornell University Press; 2010.

29. Harsha J. Conflicts and dilemma of human right to water. Current Science 2011; 100(12):1778-1780

30. Office of the High Commissioner for Human Rights (OHCHR). Special Rapporteur on human rights and the environment (former Independent Expert on human rights and the environment). Geneva: OHCHR; 2015.

31. United Nations General Assembly (UNGA). Human rights obligations related to access to safe drinking water and sanitation. Note by the secretary-general. Geneva: UNGA; 2010. UN Document A/65/254.

32. Yang H, Bain R, Bartram J, Gundry S, Pedley S, Wright J. Water safety and inequality in access to drinking-water between rich and poor households. Environ Sci Technol 2013; 47(3):1222-1230.

33. Satterthwaite D. MDG experience regarding improved drinking water, sanitation and slums and the lessons for implementation of the post 2015 agenda. [cited 2015 Aug 15]. Available from: https://wess.un.org/wp-content/uploads/2014/11/DevEnv2015-Satterthwaite.pdf

34. de Albuquerque C, Roaf V. On the right track. Good practices in realising the rights to water and sanitation. Lisbon: ERSAR; 2012.
35. Luh J, Baum R, Bartram J. Equity in water and sanitation: Developing an index to measure progressive realization of the human right. Int J Hyg Environ Health 2013; 216(6):662-671.

36. Bain R, Cronk R, Hossain R, Bonjour S, Onda K, Wright J, Yang H, Slaymaker T, Hunter P, Prüssustün A, Bartram J. Global assessment of exposure to faecal contamination through drinking water based on a systematic review. Trop Med Inter Health. 2014; 19(8):917927.

37. Meier BM, Kim Y. Human Rights Accountability through Treaty Bodies: Examining Human Rights Treaty Monitoring for Water and Sanitation. Duke Journal of Comparative \& International Law 2015; 26(1):1-78.

38. Nallari A. "All we want are toilets inside our homes!" The critical role of sanitation in the lives of urban poor adolescent girls. Environment and Urbanization 2015; 27(1):1-16.

39. World Health Organization (WHO). WHO/UNICEF Joint Monitoring Programme for Water Supply and Sanitation. Progress on drinking water and sanitation - 2015 Update and MDG Assessment. Geneva: WHO Press; 2015.

40. United Nations World Water Assessment Programme (WWAP). World Water Development Report 2015: Water for a Sustainable World. Paris: Unesco; 2015.

41. Paim JS. O que é o SUS. Rio de Janeiro: Fiocruz; 2009.

42. Clark C. The centrality of community participation to the realization of the right to water. In: Sultana F, Loftus A, editors. The right to water: politics, governance and social struggles. New York: Earthscan, 2012. p. 174-189.

43. Berry KA and Mollard E. Social Participation in Water Governance and Management. London: Earthscan; 2010.

44. De Albuquerque C, Roaf V. On The Right Track. Good Practices in Realising the Rights to Water and Sanitation. Lisbon: Textype; 2012.

45. Heller L. The crisis in water supply: how different it can look through the lens of the human right to water? $\mathrm{Cad}$ Saude Publica 2015; 31(3):447-449.

Artigo apresentado em 11/08/2015

Aprovado em 03/12/2015

Versão final apresentada em 05/12/2015 